Original Article

\title{
Single Burr Hole Evacuation of Extradural Hematoma in Pediatric Population: An Experience from the Biggest Children Hospital of Pakistan
}

\author{
Mian Awais ${ }^{1}$, Akhtar Muner ${ }^{1}$, Lubna ljaz ${ }^{1}$, Laeeq-ur-Rehman ${ }^{1}$, Ubaid-ur-Rahman ${ }^{1}$, Rimla Ayesha ${ }^{2}$ \\ ${ }^{1}$ The Children's Hospital \& The Institute of Child Health, Lahore \\ ${ }^{2}$ Mujahid Hospital, Faisalabad - Pakistan
}

\begin{abstract}
Objective: To observe the outcome of single burr hole evacuation of EDH in a pediatric population.

Material and Methods: We included 52 children who had had a head injury and were diagnosed with EDH on a CT scan. Over three months, they were all admitted to the pediatric neurosurgery ward. Serial CT scans and neurological evaluations were performed on all of the youngsters regularly to monitor their progress.
\end{abstract}

Results: 52 pediatric and adolescent patients were included. The age range was 6 months to 18 years. There were 30 male and 22 female patients. All of the children have EDH as a result of head injuries sustained in various accidents. All of the youngsters underwent surgery to remove EDH through a single burr hole. On the second postoperative day, five infants underwent reoperation owing to neurological deterioration, and two children died. The result was good (mRS 0) in 44/52 (84.6\%) instances, mild deficits (mRS 1-2) in 4/52 (7.6\%), and severe impairments (mRS 3-5) in 2/52 (3.84\%) cases six months after the event.

Conclusion: Although, EDH is a life-threatening surgical disease if not treated promptly, EDH evacuation by a single burr hole has a satisfactory prognosis in the juvenile population, with fewer complications and recurrences.

Keywords: Extradural Hematoma (EDH), Burr Hole, Computed Tomography.

\section{Corresponding Author: Mian Awais}

The Children's Hospital \& The Institute of Child Health,

Lahore - Pakistan

Email:mian.awais00@gmail.com

Date of Submission: 15-08-2021

Date of Revision: 10-09-2021

Date of Acceptance: 12-09-2021

Date of Online Publishing: 30-9-2021

Date of Print: 30-9-2021
DOI: $10.36552 /$ pjns.v25i3.588

\section{INTRODUCTION}

Epidural hematoma (EDH) accounts for approximately $2-3$ percent of all head injuries and $1-6$ percent of all diagnoses in children hospitalized following traumatic brain injury in the pediatric population. ${ }^{1-6}$ They are classified as a serious neurosurgery emergency that requires prompt diagnosis and treatment. Head traumas not only cause primary damage to the brain 
parenchyma, but they can also result in the development of an intracranial hematoma $(\mathrm{ICH})$. $\mathrm{ICH}$ can induce compression of the brain parenchyma as well as intracranial structural displacement, which can lead to herniation, unconsciousness, and death. It can occur as an epidural hematoma (EDH) or a subdural hematoma $(\mathrm{SDH})$ in the intra-axial compartment (inside the brain) or extra-axial compartment (outside the brain) (SDH). The epidural hematoma affects $0.5-12 \%$ of patients with moderate to severe head injuries, ${ }^{7-12}$ while subdural hematoma affects 12 to $18 \% .^{12-14}$

The kind of hematoma, size, and location of $\mathrm{ICH}$, as well as the degree of the accompanying primary brain damage, all influence the clinical prognosis of intracranial hemorrhage $(\mathrm{ICH}) .{ }^{7,9,11}$ Previous research has suggested that a shorter period between trauma and hematoma removal improves clinical results. ${ }^{7,15,16}$ With EDH, total morbidity and death vary from 12 to $41 \%$. ${ }^{7,8,17}$ This study was aimed to observe the outcome of single burr hole evacuation of EDH in pediatric and adolescent patients.

\section{MATERIAL and METHODS}

\section{Study Design \& Setting}

A case-control study was designed and conducted from May 2021 to July 2021, 52 children and adolescents with EDH were included at the Pediatric Neurosurgery Department at The Children's Hospital and the Institute of Child Health in Lahore. All children hospitalized to the Neurosurgery Department following a trauma had their brains scanned and were diagnosed with $\mathrm{EDH}$.

\section{Inclusion Criteria}

The study included all children and adolescents up to the age of 18 years who were admitted with a cerebral extradural hematoma.
Adult patients more than 18 years excluded. Cases with GCS < 5 also excluded. Further, posterior fossa EDH cases were also excluded.

\section{Data Collection}

Neurological and radiological evaluations were assessed. Information was gathered on the following: age, gender, GCS at admission, mechanisms of injury, the thickness of extradural hematoma and its and location, midline shift, treatment strategy, mRS (modified Rankin Scores), and hospital stays.

\section{Evaluation of Outcome}

The outcome was assessed from the modified Rankin Scale (mRS). Score $0=$ for no symptom; Scores: $1-2$ = slight disability; Scores: $3-5=$ moderate to server disability and Score 6: death.

\section{Assessment and Prompt Treatment}

The surgical choice was made based on neurological (GCS - Glasgow Coma Scale) and radiological results. The majority of the children were operated on right away, within 3-4 hours of admission, while some were operated on after more than 12 hours. The single burr hole EDH evacuation was given to all children who had surgical therapy.

\section{Surgical Follow-up}

When children required anesthesia and ventilation following surgery, they were followed in the pediatric critical care unit (ICU). On release and six months following hospitalization, all of the children were neurologically assessed using mRS.

\section{Exclusion Criteria}




\section{RESULTS}

\section{Age \& Gender Distribution}

The youngsters ranged in age from 6 months to 18 years old, with 30 males and 22 females. At the time of admission, the average age was 6.7 years (minimum 6 months, maximum 18 years). Most patients (38\%) were between 5and 10 years. $11.5 \%$ were less than 1 year, $23 \%$ were between $1-4$ years and $27 \%$ were between $10-18$ years (Table 1).

Table 1: Age and gender pediatric patients $(n=52)$.

\section{Gender/Age Groups}

Male patients

Female patients

$<\square 1$ year

$1-4$ years

$5-10$ years

$10-18$ years

Median age $=6.7 \square$ years

\section{The severity of Head Injury}

Patients were categorized into 3 groups depending upon the intensity of head injury namely mild-moderate and severe head injury. The majority of the patients $48 \%$ had mild head injuries (14-15GCS) followed by moderate injuries (35\%) with $9-13$ GCS and only $17.3 \%$ had severe head injuries having GCS of less than 8/15. The median GCS was 12.5/15 (Table 2).

Table 2: GCS at admission.

$\begin{array}{lcl}\begin{array}{l}\text { Severity of Head } \\ \text { Injury }\end{array} & \text { GCS } & \begin{array}{c}\text { Number of } \\ \text { Patients }\end{array} \\ \text { Mild } & 14-15 \text { GCS } & 25 / 52(48.07 \%) \\ \text { Moderate } & 9-13 \text { GCS } & 18 / 52(34.61 \%) \\ \text { Severe } & <8 \text { GCS } & 09 / 52(17.3 \%) \\ \text { Median GCS at admission }=12.5 & \end{array}$

\section{Information of EDH}

Location of EDH varied. Location of $23 \% \mathrm{EDHs}$ was in the Frontotemporal region, $53.8 \%$ in
Parietotemporal, $15 \%$ in Temporal, and $7.69 \%$ in Occipital locations. The Mean midline shift was $2 \mathrm{~mm}$. And Mean EDH thickness was $14.6 \mathrm{~mm}$. The duration of hospital stays varied between 3-12 days (Table $\mathbf{3}$ ).

Table 3: Radiologic data of the extradural hematoma $(E D H)$ included in the study $(n=52)$.

\begin{tabular}{|c|c|c|c|}
\hline Information & EDH Location & $\begin{array}{l}\text { No. of } \\
\text { Patients }\end{array}$ & $\begin{array}{c}\text { Duration of } \\
\text { Hospital } \\
\text { Stay (days) }\end{array}$ \\
\hline \multirow{4}{*}{$\begin{array}{l}\text { on: } \\
\text { Extradural } \\
\text { Hematoma }\end{array}$} & Frontotemporal & $12(23 \%)$ & 03 \\
\hline & Temporal & 08 (15\%) & 3.5 \\
\hline & Parietotemporal & 28 (53.8\%) & 3.5 \\
\hline & Occipital & 4 (7.69\%) & 12 \\
\hline \multicolumn{4}{|c|}{$\begin{array}{l}\text { Mean EDH Thickness }=14.6 \mathrm{~mm} \\
\text { Mean Midline Shift }=02 \mathrm{~mm}\end{array}$} \\
\hline
\end{tabular}

\section{Modified Rankin Scale}

The modified Rankin Scale (mRS) was zero in $76.9 \%$ patients at the time of discharge and was $1-2$ in $15.3 \%$ and $3-5$ in $3.8 \%$ patients. At six months after discharge, the mRS was zero in $84.61 \%$ of patients, $1-2$ in $7.6 \%$ of patients, and $3-5$ in 3.8\% patients (Table 4).

Table 4: Modified Ranking Scores $(n=52)$.

\begin{tabular}{|lll}
$\begin{array}{l}\text { Modified Ranking } \\
\text { Scale (Time) }\end{array}$ & mRS Scores & Prevalence \\
& mRS 0 & $40(76.9 \%)$ \\
Discharge & $m R S 1-2$ & $08(15.3 \%)$ \\
& $m R S 3-5$ & $02(3.8 \%)$ \\
6 Months After & $m R S 0$ & $44(84.61 \%)$ \\
Discharge & $m R S ~ 1-2$ & $04(7.6 \%)$ \\
& $m R S 3-5$ & $02(3.8 \%)$ \\
\hline
\end{tabular}

\section{DISCUSSION}

$\mathrm{EDH}$ is a life-threatening medical condition in children, but it may be treated both surgically and conservatively with great results because of global access to sophisticated imaging facilities. The Origins of Even when the fall is from a height of less than $1 \mathrm{~m}$, falls from the roof and stairs are 
the most reported reasons of $\mathrm{EDH}^{18}$ Motor vehicle accident is the second most common cause. EDH is most typically seen in a familiar setting ${ }^{19,20}$ and frequently after mild head trauma. Some of these youngsters arrived in the emergency room with a worsening state of consciousness, headache, or nausea, but no specific neurological abnormalities. EDH can be difficult to diagnose because of its mild presenting signs.

A male predominance has also been found, which has been documented in the literature. ${ }^{20-21}$ It was also verified in our study, with 58 percent of children being males. EDH is a blood clot that forms between the inner table of the skull and the outer layer of the dura. ${ }^{22}$ In around $70-80$ percent of children, EDH is primarily seen in the temporoparietal region, but it can also extend into the neighboring frontal area, as demonstrated in our study. ${ }^{23}$ Arterial damage is the most common cause of bleeding in $E D H$, is frequently caused by a skull fracture, which is a typical finding in EDH. In other studies, the findings were comparable, with skull fracture rates ranging from 48 to 90 percent. ${ }^{19-20}$

The lucid period of EDH was described by Pasaoglu et al, in $32 \%$ of their pediatric patients, ${ }^{24}$ whereas it was seen in $06 / 52(11 \%)$ of the cases in our research. A clinical deterioration that develops more than 3 days after trauma is described as late, ${ }^{18}$ in contrast to this early development of symptoms. While an EDH enlargement causes early deterioration, the delayed deterioration is mostly due to subsequent cerebral edema and a protracted mass impact. In our study, a delayed worsening was seen in $08 / 52$ (15.38 percent) of the patients, and 05 of these children required surgical evacuation.

EDH treatment, whether surgical or conservative, is a contentious subject, and there are no universally recognized standards for the clinical management of these children. Blood volume $>30 \mathrm{ml}$, clot thickness $>15-18 \mathrm{~mm}$, and midline displacement $>4-5 \mathrm{~mm}$ are all factors that favor surgical indications. ${ }^{15-16}$ When the clotting thickness is less than $1 \mathrm{~cm}$, the clot anteroposterior diameter is less than $3 \mathrm{~cm}$, there is no shift, and there are no neurologic impairments, conservative therapy is recommended. ${ }^{20,25,26}$ Nonetheless, Balmer et al, documented a series of infants with EDH more than $1 \mathrm{~cm}$ who were managed conservatively, demonstrating that size alone is not a strong reason for surgery. ${ }^{7}$ We chose surgical criteria mostly because of mid-line displacement, EDH thickness, and poor GCS.

In our study, surgical therapy did not result in any morbidity or problems, which are consistent with earlier findings. ${ }^{20}$ Six months after discharge, 84 percent of all EDH had a good result (mRS 0). These findings are consistent with other recent studies of children who have undergone surgery. ${ }^{18-20}$

\section{CONCLUSION}

Because $E D H$ is a potentially fatal disease, evacuation of EDH through a single burr hole has a favorable prognosis in children, with fewer risks of recurrence and complications.

\section{REFERENCES}

1. Ammirati $\mathrm{M}$, Tomita $\mathrm{T}$. Posterior fossa epidural hematoma during childhood. Neurosurgery, 1984; 14: $541-4$.

2. Carcassonne M, Choux M, Grisoli F. Extradural hematomas in infants. J Pediatr Surg. 1977; 12: 6973.

3. dos Santos $A L$, Plese JP, CiquiniJúnior $O$, Shu EB, Manreza LA, Marino Júnior R. Extradural hematomas in children. Pediatr Neurosurg. 1994; 21: $50-4$.

4. Gallagher JP, Browder EJ. Extradural hematoma. Experience with 167 patients. J Neurosurg. 1968; 29: 1-12.

5. Mazza C, Pasqualin A, Feriotti G, Da Pian R. Traumatic extradural haematomas in children: 
experience with 62 cases. Acta Neurochir. 1982; 65: 67-80.

6. Parslow RC, Morris KP, Tasker RC, Forsyth RJ, Hawley CA. Epidemiology of traumatic brain injury in children receiving intensive care in the UK. UK Paediatric Traumatic Brain Injury Study Steering Group; Paediatric Intensive Care Society Study Group. Arch Dis Child, 2005; 90: 1182-1187.

7. Seelig JM, Becker DP, Miller JD, Greenberg RP, Ward JD, Choi SC: Traumatic acute subdural hematoma: major mortality reduction in comatose patients treated within four hours. N Engl J Med. 1981; 304: 1511-8.

8. Jamieson RG, Yelland JDN: Extradural hematoma: report of 167 cases. J Neurosurg. 1968; 29: 13-23.

9. Lobato RD, Rivas JJ, Cordobes F, et al: Acute epidural hematoma: an analysis of factors influencing the outcome of patients undergoing surgery in coma. J Neurosurg. 1988; 68: 48-57.

10. McKissock W, Taylor JC, Bloom WH, Till K: Extradural haematoma: observation on 125 cases. Lancet, 1960; 2: 167-72.

11. McLaurin RL, Ford LE: Extradural hematoma: statistical report of 47 cases. J Neurosurg. 1964; 21: 364-71.

12. Marshall LF, Gautille T, Klauber MR, et al. The outcome of severe closed head injury. J Neurosurg. 1991; 75: S28-S36.

13. Wilberger JE, Harris M, Diamond DL. Acute subdural hematoma: morbidity and mortality related to timing of operative intervention. J Trauma, 1990; 30: 733-6.

14. Gutman MB, Moulton RJ, Sullivan I, Hotz G, Tucker WS, Muller PJ: Risk factors predicting operable intracranial hematomas in head injury. J Neurosurg. 1992; 77: 9-14.

15. Kaufman $H H$, Makela $M E$, Lee KF, Haid RW, Gildenberg PL. Gunshot wounds to the head: a perspective. Neurosurgery, 1986; 18: 689-95.

16. Nehls DG, Mendelow AD, Graham DI, Teasdale GM. Experimental intracerebral hemorrhage: early removal of a spontaneous mass lesion improves late outcome. Neurosurgery, 1990; 27: 674-82

17. Seelig JM, Marshall LF, Toutant SM, et al. Traumatic acute epidural hematoma: unrecognized high lethality in comatose patients. Neurosurgery, 1984; 15: 617-9.

18. Balmer B, Boltshauser E, Altermatt S, Gobet R. Conservative management of significant epidural haematomas in children. Childs Nerv Syst. 2006; 22: 363-7.

19. Ersahin Y, Mutluer S, Güzelbag E. Extradural hematoma: analysis of 146 cases. Childs Nerv Syst. 1993; 9: 96-9.

20. Gerlach R, Dittrich S, Schneider W, Ackermann H, Seifert V, Kieslich M. Traumatic epidural hematomas in children and adolescents: outcome analysis in 39 consecutive unselected cases. Pediatr Emerg Care, 2009; 25: 164-9.

21. Stieg $P E$, Kase $C S$. Intracranial hemorrhage: diagnosis and emergency management. Neurol Clin. 1998; 16: 373-90.

22. Agrawal A, Agrawal CS, Kumar A, Adhikari S: Outcome of traumatic extradural haematoma managed surgically: Our experience. NJOT. 2007; 6 (2): 74-76,

23. Husain $M$, Ojha BK, Chandra AM, Singh A, Singh G, Chugh A, Rastogi M, Singh K: Contralateral motor deficit in extradural hematoma: Analysis of 35 Patients. Indian Journal of Neurotrauma (IJNT), 2007; 4 (1): 41-44,

24. Pasaoglu A, Orhon C, Koc K, Selcuklu A, Akdemir $\mathrm{H}$, Uzunoglu $\mathrm{H}$. Traumatic extradural haematomas in pediatric age group. Acta Neurochir. 1990; 106: 136-9.

25. Beni-Adani L, Flores I, Spektor S, Umansky F, Constantini S. Epidural hematoma in infants: a different entity? J Trauma Acute Care Surg. 1999; 46: 306-11.

26. Bullock MR, Chesnut R, Ghajar J, Gordon D, Hartl R, Newell DW. Surgical management of acute epidural hematomas. Neurosurgery, 2006; 58 (Suppl. 3): 7-15. 


\section{Additional Information}

Disclosures: Authors report no conflict of interest.

Ethical Review Board Approval: The study was conformed to the ethical review board requirements.

Human Subjects: Consent was obtained by all patients/participants in this study.

Conflicts of Interest:

In compliance with the ICMJE uniform disclosure form, all authors declare the following:

Financial Relationships: All authors have declared that they have no financial relationships at present or within the previous three years with any organizations that might have an interest in the submitted work.

Other Relationships: All authors have declared that there are no other relationships or activities that could appear to have influenced the submitted work.

\section{AUTHORS CONTRIBUTIONS}

\begin{tabular}{|l|l|l|}
\hline Sr.\# & Author's Full Name & Intellectual Contribution to Paper in Terms of: \\
\hline 1. & Mian Awais & Study design and methodology. \\
\hline 2. & Akhtar Muner & Paper writing, referencing and data calculations. \\
\hline 3. & Lubna ljaz & Data collection and calculations. \\
\hline 4. & Laeeq-ur-Rehman & Analysis of data and interpretation of results etc. \\
\hline 5. & Ubaid-ur-Rahman & Literature review and referencing. \\
\hline 6. & Rimla Ayesha & Analysis of data and quality insurer. \\
\hline
\end{tabular}

